\title{
QUADRINHOS DIGITAIS: \\ UMA PROPOSTA LÚDICA NO ENSINO EM ENFERMAGEM
}

\author{
Karen Cardoso Caetano ${ }^{1}$ \\ Gilse Antoninha Morgental Falkembach ${ }^{2}$
}

\section{RESUMO}

Este estudo aborda a criação de um protótipo a partir do planejamento e da modelagem de um material educativo digital, no formato de histórias em quadrinhos, tendo como conteúdo situações encontradas pelo aluno de Enfermagem durante sua vivência no campo de estágio. O objetivo da aplicação educacional é auxiliar o aluno na tomada de decisão, e na análise crítica do contexto das situações propostas, utilizando os aspectos teóricos de resolução de problemas. O aplicativo educacional foi planejado e idealizado tomando por base teórica Piaget e a sua visão sobre os mecanismos que as atividades lúdicas desencadeiam no indivíduo. A metodologia utilizada para a criação do protótipo segue as seguintes etapas: delimitação do problema, proposta dos objetivos, delimitação do público alvo, busca e seleção do conteúdo da aplicação e os subsídios para o embasamento teórico.

Palavras-chave: Informática na Educação, Educação em enfermagem , Tomada de decisão em enfermagem, Quadrinhos digitais

\section{COMICS DIGITAL : A LUDIC PROPOSALIN IN NURSE THEACH}

\section{SUMMARY}

This study is the result of an educational digital applicative planning, in the sharp of comics, having as content of the learning, situations found by Nursing student during his living into the field of training. The goal for the use of this applicative will be help the pupils in making decision, and in the critic analyze of the content of the proposal situations, utilizing the theoretical aspects of the problems resolution. The educational applicative was planned and idealized according Piaget theoretical base and his point of view about the mechanism that ludic activities unleash in the individual. The methodology follows the following steps: the problem delimitation, the aims proposal, search and selection of the application content, and theoretical foundation.

Keywords: informatics in Education, Education in nursing, making decision in Nursing, digital comics.

\footnotetext{
${ }^{1}$ Enfermeira, Mestranda EEUSP, Especialista em Informática na Educação(UFRGS) e Metodologia do Ensino Superior (UNASP) e-mail:karencaetano@uol.com.br.

${ }^{2}$ Engenheira Civil, Doutora em Informática na Educação (UFRGS), Mestre em Informática (PUC-RJ).email:gilsenf@terra.com.br 


\section{INTRODUÇÃO}

Brincar significa divertir-se, recrear-se. Brincadeira é o ato ou o efeito de brincar. Segundo o dicionário Houaiss, brincadeira refere-se a jogos e brinquedos, é um passatempo, uma distração. Segundo Huizinga (2001), a brincadeira e o jogo permeiam a existência de humanos e animais, e a humanidade desde que ela existe, é a expressão de várias culturas e sociedades, manipulando imagens e dando-lhe novos significados.

Segundo Lebovici (1988), a criança brinca imitando os pais e outros adultos e através da brincadeira, trocando de papéis e tomando decisões ainda de forma espontânea faz a interação social com outras crianças aprendendo a relacionar-se e a conviver em grupo. A medida em que vai crescendo e sua forma de pensar vai ficando mais complexa, a criança vai adquirindo gosto por brincadeiras mais elaboradas e que exijam mais do seu raciocínio.(Friedmann, 1998) Jogos com regras fazem parte deste universo, então, podendo ser ou não em grupo. À medida que a criança cresce, tem a tendência de cada vez mais se distanciar das brincadeiras, envolvendo-se com a escola e outras atividades consideradas mais "produtivas". Provavelmente, a partir desse ponto invisível a criança deixa de ser criança para começar a tornar-se adolescente e adulto, deixando definitivamente as brincadeiras para trás.

\section{REFERENCIAL TEÓRICO}

\subsection{Ambiente de aprendizagem}

Atualmente a educação extrapola o ambiente escolar, não sendo mais identificado como único ambiente de aprendizagem, responsável pela formação e socialização do aluno. Ao refletir sobre os espaços em que o indivíduo pode aprender, outros agentes educacionais apresentam-se neste cenário: a comunidade, a interação com outros indivíduos e os meios de comunicação que fazem parte do ambiente de aprendizagem de jovens e crianças, influenciando e mudando comportamentos. Segundo Duarte (2003) é possível entender então que um ambiente de aprendizagem seja o espaço onde pode acontecer a transformação do conhecimento construído pelo ser humano e o cenário onde existem condições de aprendizagem e se desenvolvem capacidades, competências, habilidades e valores. Um ambiente educacional é considerado uma boa opção para a aprendizagem quando os alunos podem refletir sobre seus próprios conhecimentos em relação ao conteúdo colocado pelo professor, necessitando resolver problemas e tomar decisões, fazendo com que o conteúdo trabalhado assuma significado dentro de um contexto sócio cultural.

Duarte (2003), acredita ainda que o indivíduo aprende através de "um processo ativo,progressivo e autodirigido, que tem significado e constrói o conhecimento através das experiências dos alunos em situações reais". A mesma autora refere que o ambiente educativo ideal para o aprendizado deve ter identidade cultural com o grupo para o qual é preparado. Neste contexto cabe, além de conceituar um ambiente de aprendizagem real e tradicional como foi mencionado anteriormente, entender o que significa um ambiente de aprendizado virtual, local onde se aplica este trabalho.

Segundo Almeida (2003, p.331), ambientes digitais de aprendizagem são definidos como: 


\begin{abstract}
"Sistemas computacionais disponíveis na Internet, destinados ao suporte de atividades mediadas pelas tecnologias de informação e comunicação. Permitem integrar múltiplas mídias, linguagens e recursos, apresentar informações de maneira organizada, desenvolver interações entre pessoas e objetos de conhecimento, elaborar e socializar produções tendo em vista atingir determinados objetivos".
\end{abstract}

Apesar do computador e da Informática muito lentamente terem sido inseridos nos processos de trabalho dos enfermeiros, a prática demonstra a dificuldade do Enfermeiro em dominar essas novas tecnologias, inclusive no ensino (Évora, 1998) e (Peres,2001). A utilização de um ambiente de aprendizagem virtual disponível para alunos de enfermagem pode, no entanto, ser de grande valia no processo ensino e aprendizagem.

Segundo Gutrie (1999) e Snetinser (1993), para aprender com alegria e prazer um determinado conteúdo, os ambientes de aprendizagem estão se tornando mais amistosos e refletindo mais o mundo dos alunos.

Para a obtenção de um aprendizado significativo vale usar dos recursos oferecidos pelas tecnologias digitais para o desenvolvimento de aplicações educacionais que privilegiam, além do conteúdo a ser aprendido, a possibilidade de usar novas estratégias pedagógicas e oferecer um ensino mais empolgante que as aulas tradicionais.

\title{
2.2 A tomada de decisão no gerenciamento em Enfermagem
}

A cada ato da vida, seja pessoal ou profissional há uma consequiência, e a cada decisão tomada, um resultado. Portanto, a responsabilidade de saber tomar decisões é imensa no âmbito profissional, e é primordial para o exercício efetivo da profissão.

Segundo Guimarães e Évora (2004), a tomada de decisão é uma das características do gerenciamento e tem etapas bastante complexas, necessitando do apoio de um sistema de informação eficiente e disponível. Ciampone(1991) refere ser o processo decisório fundamental para o profissional, e ainda frisa que toda decisão deveria ser tomada de forma analítica e sistematizada, para obtenção dos melhores resultados. A autora cita Simon que explica que a decisão é um processo de cadeia de decisões e descreve as fases do processo decisório como sendo:

\section{- Percepção do problema}

É a fase em que se percebe dentro do processo de trabalho algum tipo dificuldade.

\section{- Definição do problema}

Após identificar o problema, tenta-se descrevê-lo e defini-lo melhor procurando tomar o cuidado de distinguir entre a causa e o sintoma de um problema.

\section{- Coleta de dados}

\section{- Análise dos dados}

Ao analisar os dados colhidos priorizam-se os de maior relevância, procurando assim, descobrir as causas do problema levantado.

\section{- Redefinição do problema}

Ao ser redefinido o problema pode revelar aspectos que não haviam sido observados inicialmente.

\section{- Procura de soluções alternativas}




\section{- Escolha ou decisão}

É a escolha das soluções ou alternativas encontradas para a resolução do problema.

\section{- Implementação}

Vem logo a seguir à fase anterior e é caracterizada por uma série de decisões para que a solução seja colocada em prática.

- Avaliação

A avaliação consiste em analisar os resultados alcançados ou não e a necessidade de desencadear novo processo.

A grande dificuldade em decidir reside em que muitas vezes não se tem a capacidade ou habilidade de avaliar corretamente todas as situações e variáveis envolvidas devido à inexperiência, principalmente no aspecto profissional, em que, assim como na vida, as decisões vão da complexidade mínima à máxima, sendo necessário prever as conseqüências do processo decisório. Estes aspectos mencionados com certeza geram ansiedade e angústia, principalmente durante o processo de aprendizagem nos alunos de Enfermagem, pois, compreendem desde cedo a seriedade que devem ter no processo decisório principalmente em questões que envolvam a assistência ao paciente.

Ciampone (1991) declara ainda que técnicas de jogos e dinâmicas de grupo podem auxiliar na construção do processo decisório, descrevendo e comparando técnicas tradicionais e modernas de tomada de decisão. A autora, ressaltando as técnicas modernas, seriam as que utilizam: "a técnica heurística de solução de problemas e exploração das alternativas disponíveis e consequiências, com incentivo à criatividade do grupo envolvido na decisão". (Ciampone,1991,p.203)

\subsection{O aprendizado lúdico na Educação e na Enfermagem}

Segundo Huizinga (2001), o jogo na Antigüidade, além de testar a força física, servia para ver quem tinha mais conhecimento e sabedoria. Assim eram introduzidos os enigmas como forma de testar, de forma lúdica, a capacidade que os indivíduos tinham de raciocinar e de resolver problemas.

Neste trabalho buscou-se em Piaget o embasamento para entender os mecanismos que as atividades lúdicas desencadeiam no indivíduo, a visão do autor sobre como um indivíduo processa e interioriza o conhecimento, o significado do lúdico e como as atividades lúdicas podem promover o aprendizado. Para Piaget a aquisição do conhecimento se dá através de um processo de assimilação e acomodação em relação à interação entre o indivíduo e o meio. Ao deparar-se com as dificuldades de adaptação com as situações deflagradas pelo meio, o indivíduo sofre um processo de reequilibração e assimilação de um novo esquema para lidar com a situação. Ao fazer um paralelo entre a teoria Piagetiana e processos de aprendizagem significativa, Moreira (1999), defende a transformação do material de aprendizado em algo que tenha significado para o aluno. Entendendo que o conceito de aprendizagem significativa remonta a Ausubel, que defende que uma nova informação é relacionada e ancorada a conceitos e estruturas cognitivas já existentes no indivíduo. É importante perceber que ao desenvolver materiais educativos, estes devem estar contextualizados com a cultura e o cotidiano do aluno, proporcionando assim a oportunidade de interpretar o significado da leitura da sua realidade.

No Brasil, ao analisar o uso de atividades lúdicas na Enfermagem, há poucos registros, tanto no ensino curricular envolvendo a formação dos futuros Enfermeiros, 
como na educação em saúde, envolvendo pacientes e a população em geral. As iniciativas registradas são, porém, variadas como o uso de jogos e atividades lúdicas, desenvolvidos para pacientes diabéticos aprenderem a lidar com a doença e trocarem experiências (Torres, Hortal, Schall, 2003) e os jogos para puérperas aprenderem a lidar com seus filhos (Fonseca, Scochi, Mello, 2002). O uso de jogos para promover a saúde mental em profissionais da saúde (Camargo, Bueno, 2003), ou para estimular a comunicação terapêutica entre Enfermeiro e paciente (Durman et al, 2002). O uso de jogos para auxiliar no processo de ensino e aprendizagem de administração em Enfermagem, na graduação, também já foi objeto de estudo, sendo utilizado jogos de raciocínio, de competição, cooperação e estratégia, sob a direção do professor. (Takahashi, Peres,2000). Apesar destas iniciativas, parece haver uma grande lacuna no desenvolvimento e no registro de atividades lúdicas com objetivo educacional, no formato tradicional ou digital na formação profissional acadêmica de Enfermeiros.

\subsection{As histórias em quadrinhos como instrumento de aprendizagem}

Para compreender a evolução das histórias em quadrinhos e a sua utilização é necessário conhecer um pouco da sua origem e história que remonta aos séculos XVIII e XVIIII, quando ilustradores, que eram originários da Alemanha, França e Suíça, desenhavam cenas do cotidiano em que se percebia uma espécie de roteiro. Dentre os precursores da história em quadrinhos destacam-se Hogart, Töpffer, Busch, Colomb. No início, este tipo de arte era chamado de histórias em imagens, originado de simples ilustrações que posteriormente deram origem ao "cartoon" e envolviam caricaturas, desenhos simples e rudimentares e histórias cômicas. A primeira história em quadrinhos é considerada de autoria de Colomb em 1889 e denominava-se a "Família Fenouillard", sendo esse trabalho seguido de muitos outros nos anos seguintes.

No Brasil o primeiro "cartoon" apareceu em 14 de dezembro de 1837 , feito por Manuel A. Porto-Alegre. A primeira revista ilustrada foi criada em 1876 por Angelo Agostini, seguida pelo Jornal da Infância em 1898, e da revista "Tico-tico", criada em 1905 e lida por várias gerações de crianças brasileiras.

$\mathrm{Na}$ evolução dos quadrinhos dentro do cenário mundial e brasileiro, percebe-se que não há limites para os temas abordados utilizando essa técnica de comunicação. $\mathrm{O}$ uso dos quadrinhos impressos surge, portanto, como meio de comunicação com fins educacionais, e atualmente os quadrinhos digitais, ou seja, quadrinhos feitos e vistos no computador, se bem utilizados podem ser um recurso rico em possibilidades pedagógicas.

\section{ESTRUTURA DE UMA APLICAÇÃO HIPERMÍDIA}

Neste trabalho foram feitos a modelagem e a construção do protótipo de um material educativo digital, no formato de histórias em quadrinhos. Esse protótipo servirá de base para o desenvolvimento da aplicação hipermídia que será realizado no curso de Mestrado da autora e que terá como objetivo facilitar e promover o aprendizado relacionado à tomada de decisões, na disciplina de Administração em Enfermagem. 


\subsection{Objetivos da aplicação}

\section{Geral}

- Auxiliar o aluno na tomada de decisão através do uso de instrumento lúdico digital.

\section{Específico}

- Auxiliar o aluno na tomada de decisão frente à situações emergenciais e rotineiras, de natureza relacional, assistencial, e de gerenciamento de recursos humanos e materiais.

- Propiciar aprendizagem contextualizada auxiliando a identificar situações-problema e a desenvolver o pensamento crítico para resolvê-las.

\subsection{Metodologia para a aplicação}

Método, segundo (Oliveira, 2000) "é o caminho pelo qual se atinge um objetivo". Para descrever o método com que foi planejado e com o qual será implementada a aplicação, será preciso descrever as etapas abaixo:

- Delimitação do problema;

- Proposta dos objetivos;

- Delimitação do público alvo;

- Busca e seleção do conteúdo da aplicação e do embasamento teórico;

- Escolha da metodologia de utilização;

- Escolha dos recursos e mídias utilizadas;

- Construção do roteiro baseado nas vivências dos alunos de uma universidade pública;

- Construção do Storyboard;

- Implementação

- Avaliação e Manutenção

- Distribuição

\subsection{Conteúdo da aplicação}

O conteúdo da aplicação refere-se aos aspectos teóricos da tomada de decisão em Enfermagem, aplicados a situações vivenciadas pelos alunos, tais como as relações interpessoais na equipe de saúde, os conflitos de relacionamento, os processos de trabalho, o planejamento da assistência e seus percalços. A ementa da disciplina contempla vários aspectos além da do processo decisório, podendo ser mencionados:

- Teorias de administração aplicadas à Enfermagem;

- Filosofia e estrutura organizacional;

- Meios e instrumentos do processo de trabalho de administrar da Enfermagem: recursos humanos, materiais, físicos, financeiros, sistema de informação, planejamento, processo de mudança, introdução ao processo grupal (papéis no campo grupal, conflitos, resistências e negociação).

\subsection{Público alvo}

Alunos do $3^{\circ}$ semestre do curso de graduação em Enfermagem 
3.5 Mídias utilizadas

A aplicação utilizará mídias de texto, som, imagem e clips que serão construídos com o auxílio do software Flash MX e Action Script.

\subsection{Locais e formas de aplicação}

O material educativo proposto será utilizado como mais um recurso didático, no desenvolvimento da disciplina de Administração do curso de graduação em Enfermagem da Escola de Enfermagem da Universidade de São Paulo. A aplicação deve ser utilizada durante o desenvolvimento da parte teórica de tomada de decisão em Enfermagem e durante o desenvolvimento das aulas práticas quando o aluno começa a praticar seus conhecimentos. É uma maneira de ao mesmo tempo em que vivencia a realidade, resgata através dos quadrinhos, vários aspectos da tomada de decisão. O aluno poderá acessar sozinho as histórias em quadrinhos, e depois poderá ter momentos de discussão com o professor e/ou colegas, através de chats ou através de fórum.

\section{CONSTRUÇÃO DO PROTÓTIPO}

Para construir o protótipo foi preciso desenvolver um storyboard, no qual são explicitados o roteiro e os personagens.

\subsection{Os roteiros}

A escolha do roteiro baseia-se em experiências vividas pelos próprios alunos, norteadas pelos temas que mais prevaleceram no estágio que realizaram. Para a construção do protótipo foi escolhido o roteiro I. Os outros roteiros fazem parte do planejamento, porém sua implementação será na fase seguinte do trabalho.

\section{Roteiro I}

Personagem principal é procurada por duas auxiliares que reclamam por não terem recebido os dias de folga nas datas solicitadas. Uma delas é bastante objetiva e um pouco agressiva, a outra parece calma, mas faz críticas ao hospital e à chefia anterior.

Pontos a ponderar:

- Erro na escala

- Necessidade do serviço

- Postura

- Manipulação de opinião

\subsection{Os personagens}

O aluno irá visualizar os personagens que fazem parte da rotina diária da Enfermeira e através dos personagens vivenciar suas próprias dúvidas e incertezas. $\mathrm{Na}$ aplicação, os personagens serão representados por figuras humanas caricaturadas nos quadrinhos digitais.

\subsection{Metodologia para o desenvolvimento do protótipo}


Após a delimitação do tema, da escolha do público alvo e de leituras para a realização deste trabalho, optou-se pela criação de um protótipo que agrega um dos conteúdos de Enfermagem da disciplina de Administração I (estudos de casos e exercícios de tomada de decisões relativos aos estudos). Para isto foi escolhido o uso dos quadrinhos digitais, por aproximar-se mais de uma linguagem cotidiana do aluno, tentando, de forma lúdica, reproduzir sua realidade de uma forma mais próxima, ao contrário de uma exposição acadêmica sobre o assunto, em que o aluno visualiza a realidade através das lentes do professor e da sua vivência apenas.

A escolha de um software que atendesse as necessidades da equipe executora do aplicativo evidenciou-se por suas características e versatilidade. Uma das preocupações da equipe foi com a velocidade e tamanho dos arquivos gerados, e que sendo hospedados na Internet, poderiam levar muito tempo para serem carregados. Por esses motivos descritos optou-se pelo uso do software Flash MX e Action Script.

Os desenhos foram executados diretamente na tela, não utilizando nenhum outro programa auxiliar.

\subsection{Storyboard do protótipo}

O storyboard representa um esboço do modelo do protótipo e mostra como seus elementos estarão organizados, é um "rascunho" para a implementação.

Para construir o storyboard foram seguidas as etapas:

- $\quad$ Organização do conteúdo, relacionado ao tema da aplicação;

- Determinação das estruturas de acesso, ou seja, o controle da navegação;

- $\quad$ Especificação do conteúdo a ser exibido e as mídias a serem utilizadas em cada tela. As telas são representadas por quadros e cada quadro do storyboard mostra o conteúdo desta tela.

\section{RESULTADOS ESPERADOS}

Neste trabalho não se podem verificar os resultados esperados de um material digital por tratar-se do planejamento da ferramenta e da implementação do protótipo 
baseada apenas em um dos roteiros propostos. Posteriormente, ao ser implementado será feito um estudo de caso com a utilização do aplicativo no público alvo previsto. $\mathrm{O}$ processo de avaliação da ferramenta fará parte da dissertação de Mestrado da autora desta monografia, como continuação do desenvolvimento de um ambiente de aprendizagem virtual à distância. Espera-se poder implementar a aplicação a partir do planejamento proposto. A avaliação e a validação da ferramenta possibilitam que a mesma possa ser utilizada segundo as necessidades reais do público alvo, de maneira que possa alcançar os objetivos propostos no planejamento.

Espera-se, principalmente, desenvolver a capacidade de análise crítica do aluno e do grupo, através das discussões geradas pela aplicação e que através delas possam despertar e mobilizar aspectos culturais, éticos e emocionais do aluno.

\section{CONCLUSÃO}

O uso de uma ferramenta que seja atraente para o aluno, buscando sair da rotina das aulas expositivas e monótonas, parece ser o caminho a ser trilhado por professores e alunos. Para auxiliar na aprendizagem e formação dos alunos, é necessário que o conteúdo seja trabalhado de acordo com a realidade e o cotidiano enfrentado e visualizado por eles. Além disso, deve levá-los à reflexão, tanto quanto indivíduo inserido nesta realidade como grupo. Ao refletir e discutir as soluções para os problemas encontrados, o aluno passa a incorporar um pouco destas soluções em sua vivência e passa a acomodar e adaptar novas e antigas situações que poderiam causarlhe estresse ou insegurança. O uso da tecnologia como ferramenta para a utilização de uma metodologia que use aspectos lúdicos, reforça a necessidade da contextualização do ensino em todos os aspectos, pois a sociedade cada vez mais tem incorporado o computador no seu dia a dia. $\mathrm{O}$ uso do computador como ferramenta no ensino das mais variadas áreas do conhecimento vem se disseminando, e dentro da Enfermagem a sua utilização também vem crescendo.

Conclui-se, após todas as considerações anteriores, que a utilização de aplicativos educacionais no ensino da Enfermagem pode auxiliar e facilitar a aprendizagem do aluno, estimulando a criatividade, a discussão, e contribuindo para que, através do lúdico, ele possa entender melhor a sua realidade.

\section{REFERÊNCIAS}

ALMEIDA, M. E. B. Educação à distância na Internet: abordagens e contribuições dos ambientes digitais de aprendizagem, Revista Educação e Pesquisa, São Paulo, v.29, p.327-340, jul./dez. 2003

CAMARGO, R. A. A. de, BUENO, S. M. V. Lazer, a vida além do trabalho para uma equipe de futebol entre trabalhadores de hospital Rev. Latino-Am. Enfermagem. [online] Jul/Ago 2003, vol.11, no.4 Disponível em:

www<http://www.scielo.br/scielo.php?script=sci_arttext\&pid=S010411692003000400 012\&lng=en\&nrm=iso >. ISSN 0104-1169. Acesso em jul de 2003.

DUARTE ,J. Learning environments. A conceptual approach. . Estudos pedagógicos [online]. 2003, no.29 Disponível em: 
$<$ http://www.scielo.cl/scielo.php?script=sci_arttext\&pid=S071807052003002900007\&1 ng=en\&nrm=iso >. ISSN 0718-0705 Acesso em nov de 2004.

DURMAN, S.; DIAS, D.C.; STEFANELLI, M.C. Validação de jogo educativo para discussão da comunicação terapêutica. Revista eletrônica de Enfermagem,v.n.p.1013,2002, disponível na www < http:/www.fen.ufg.br> Acesso em out de 2004.

ÉVORA, Y.D.M. O Paradigma da Informática em Enfermagem. Ribeirão Preto, 1998. Tese (Livre Docência) - Escola de Enfermagem de Ribeirão Preto, Universidade de São Paulo

GUIMARÃES E.M.P. ; ÉVORA, Y. D.M. Sistemas de Informação: instrumento para a tomada de decisão no exercício da gerência. Ci. Inf., Brasília, v.33, n.1, p.72-80, jan./abril 2003

GUTHRIE, P. Knowledge through humor: na original approach for teaching developmental readers. In: Annual meeting of the National institute for staff and organizational development International conference on teaching and leadership excellence. Anais. Austin, 48 p. maio-1999.

HOUAISS, Dicionário eletrônico. Disponível na www < http:// uol.com.br/dicionários> Acesso em 12/2004

HUIZINGA, J. Homo Ludens São Paulo, Editora Perspectiva: 2001.

FONSECA, L. M. M.; SCOCHI, C. G. S.; MELLO, D. F. de. Educação em saúde de puérperas em alojamento conjunto neonatal: aquisição de conhecimento mediado pelo uso de um jogo educativo Rev. Latino-Am. Enfermagem. [online]. Mar./Abr. 2002, vol.10, no.2 Disponível em: http://www.scielo.br/scielo.php?script=sci_arttext\&pid=S010411692002000200007\&ln $\mathrm{g}=\mathrm{en} \& \mathrm{nrm}=\mathrm{iso}>$. ISSN 0104-1169. Acesso em set de 2004.

FRIEDMANN, A. et al O direito de brincar: a brinquedoteca. São Paulo: Edições Sociais Abrinq,1998.

CIAMPONE, M.H.T. Tomada de decisão em Enfermagem. In: KURCGANT, P. (coord.) Administração em Enfermagem. São Paulo, E.P.U.:1991, p. 191-206.

LEBOVICI, S.; DIATKINE, R. Significado e função do brinquedo na criança. Porto Alegre, Artes Médicas:1985.

MICHAELIS, Dicionário eletrônico. Disponível na www: < http://www.uol.com.br/dicionarios > Acesso em nov de 2004.

MOREIRA, M. A, Aprendizagem significativa. Brasília: Editora Universidade de Brasília:1999.

MOYA, Á. História da história em quadrinhos. Porto alegre: L \& PM, 1986. 
PIAGET, J. Teoria de Piaget. In: MUSSEN. Paul H. (org) Psicologia da criança. São Paulo: EPU/ Edusp, 1975.

OLIVEIRA, J. F. Metodologia para o desenvolvimento dos projetos de Sistemas. São Paulo: Editora Érica ,2000.

SNETSINGER, W. Use of humorous visual to enhance computer- based- instruction. In: Visula literacy in the digital age: selected readings from the Annual conference of the International visual literacy Association. Anais. p. 11 Rochester, 1993

TORRES, H. DE C.; HORTALE, V. A.; SCHALL, V. A experiência de jogos em grupos operativos na educação em saúde para diabéticos. Cad. Saúde Pública. [online].Jul/Ago. 2003, vol.19, no.4 Disponível em: www $<$ http://www.scielo.br/scielo.php?script=sci_arttext\&pid=S0102311X2003000400026\& $\operatorname{lng}=$ en\&nrm=iso $>$. ISSN 0102-311X.

TAKAHASHI, R.T.; PERES H.H.C. O desafio da utilização de técnicas pedagógicas inovadoras no ensino da Administração em Enfermagem. Revista Paulista de Enfermagem, v.19,n2, maio/ago. 2000.

TAKAHASHI, R.T.; PERES H.H.C. Tecnologia educacional: jogos aplicados ao ensino de administração em Enfermagem. In: ENCONTRO DE ENFERMAGEM E TECNOLOGIA, São Paulo,2000. Anais. São Paulo,2000,p.143-147. 